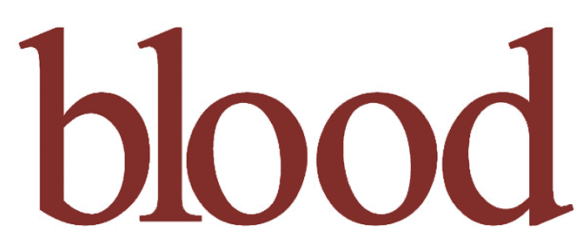

Prepublished online February 25, 2013;

doi:10.1182/blood-2012-10-461988

\title{
A dual role for Hdac1: oncosuppressor in tumorigenesis, oncogene in tumor maintenance
}

Fabio Santoro, Oronza A. Botrugno, Roberto Dal Zuffo, Isabella Pallavicini, Geoffrey M. Matthews, Leonie Cluse, Iros Barozzi, Silvia Senese, Lorenzo Fornasari, Simona Moretti, Lucia Altucci, Pier Giuseppe Pelicci, Susanna Chiocca, Ricky W. Johnstone and Saverio Minucci

Information about reproducing this article in parts or in its entirety may be found online at: http://bloodjournal.hematologylibrary.org/site/misc/rights.xhtml\#repub_requests

Information about ordering reprints may be found online at:

http://bloodjournal.hematologylibrary.org/site/misc/rights.xhtml\#reprints

Information about subscriptions and ASH membership may be found online at: http://bloodjournal.hematologylibrary.org/site/subscriptions/index.xhtml

Advance online articles have been peer reviewed and accepted for publication but have not yet appeared in the paper journal (edited, typeset versions may be posted when available prior to final publication). Advance online articles are citable and establish publication priority; they are indexed by PubMed from initial publication. Citations to Advance online articles must include the digital object identifier (DOls) and date of initial publication.

Blood (print ISSN 0006-4971, online ISSN 1528-0020), is published weekly by the American Society of Hematology, 2021 L St, NW, Suite 900, Washington DC 20036.

Copyright 2011 by The American Society of Hematology; all rights reserved.

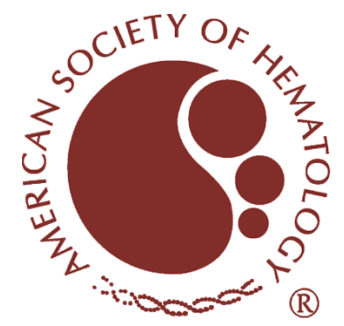




\section{A dual role for Hdac1: oncosuppressor in tumorigenesis, oncogene in tumor maintenance}

\section{Authors}

Fabio Santoro ${ }^{1 *}$, Oronza A. Botrugno ${ }^{1 *}$, Roberto Dal Zuffo ${ }^{1}$, Isabella Pallavicini ${ }^{1}$, Geoffrey M. Matthews ${ }^{5}$, Leonie Cluse ${ }^{5}$, Iros Barozzi ${ }^{1}$, Silvia Senese ${ }^{1}$, Lorenzo Fornasari ${ }^{1}$, Simona Moretti ${ }^{1}$, Lucia Altucci ${ }^{4}$, Pier Giuseppe Pelicci ${ }^{1,2}$, Susanna Chiocca $^{1}$, Ricky W. Johnstone ${ }^{5,6}$ and Saverio Minucci ${ }^{1,3 \#}$.

${ }^{1}$ Department of Experimental Oncology at the IFOM-IEO Campus, European Institute of Oncology, IEO, 20141 Milan, Italy.

${ }^{2}$ Dipartimento di Medicina, Chirurgia e Odontoiatria, University of Milan, Milan 20100, Italy

${ }^{3}$ Department of Biosciences, University of Milan 20100, Milan, Italy.

${ }^{4}$ Dipartimento di Patologia Generale, Seconda Universita’ degli Studi di Napoli, Vico

L. De Crecchio 7, 80138 Napoli, Italy

${ }^{5}$ Gene Regulation Laboratory, Cancer Therapeutics Program, The Peter MacCallum Cancer Institute, St. Andrews Place, East Melbourne 3002 Victoria, Australia

${ }^{6}$ The Sir Peter MacCallum Department of Oncology, University of Melbourne, Parkville 3054, Victoria, Australia

*These authors contributed equally to this work 
\#Corresponding authors:

Saverio Minucci, Department of Experimental Oncology, European Institute of Oncology, IFOM-IEO Campus, via Adamello 16, 20139 Milan, Italy. E-mail: saverio.minucci@ieo.eu, phone: +390257489832, fax: +390294375990

Ricky W. Johnstone, Cancer Therapeutics and Cancer Immunology Programs, The Peter MacCallum Cancer Centre, St. Andrews Place, East Melbourne, VIC 3002, Australia E-mail: ricky.johnstone@ petermac.org, phone: +61-3-9656-3727 ,fax +61$3-9656-1411$

Running title: Down-regulation of Hdac1 accelerates tumorigenesis

\section{Scientific categories: Myeloid Neoplasia}




\title{
Key Points
}

- Hdac1 and to a lesser extent Hdac2 behave as oncosuppressors during tumor initiation, while they work as oncogenes in tumor maintenance.

- Class I HDAC inhibitors (VPA) accelerate tumorigenesis in murine models of leukemia, that suggests caution in their clinical use.

\begin{abstract}
Aberrant recruitment of histone deacetylases (HDACs) by the oncogenic fusion protein PML-RAR is involved in the pathogenesis of acute promyelocytic leukemia (APL). PML-RAR, however, is not sufficient to induce disease in mice, but requires additional oncogenic lesions during the pre-leukemic phase. Here, we show that knock-down of Hdac1 and Hdac2 dramatically accelerates leukemogenesis in transgenic pre-leukemic mice. These events are not restricted to APL, since lymphomagenesis driven by deletion of $\mathrm{p} 53$, or to a lesser extent by c-myc overexpression, was also accelerated by Hdac1 knock-down. In the pre-leukemic phase of APL Hdac1 counter-acts the activity of PML-RAR in: i) blocking differentiation, ii) impairing genomic stability and iii) increasing self-renewal in hematopoietic progenitors as all of these events are affected by the reduction in Hdac1 levels. This led to an expansion of a subpopulation of PML-RAR expressing cells that is the major source of leukemic stem cells in the full leukemic stage. Remarkably, short-term treatment of pre-leukemic mice with an HDAC inhibitor accelerated leukemogenesis. In contrast, knock-down of Hdac1 in APL mice led to enhanced survival of the leukemic animals. Thus, Hdac1 has a dual role in tumorigenesis: oncosuppressive in the early stages, and oncogenic in established tumor cells.
\end{abstract}




\section{Introduction}

Epigenetic alterations are considered as relevant as genetic mutations in tumorigenesis ${ }^{1}$. Small molecules that inhibit the activity of epigenetic enzymes have the potential to revert those changes, and have entered clinical use, validating the concept of epigenetic therapy ${ }^{2}$. As an example, HDAC inhibitors (HDACi) that target multiple HDACs with non-redundant functional roles in normal and tumor cells ${ }^{3,4}$ are effective for the treatment of cutaneous $\mathrm{T}$ cell lymphoma ${ }^{2}$. Epigenetic drugs, however, have single agent efficacy only in selected hematological malignancies, underlying the need for optimized drugs/treatment strategies ${ }^{2}$. Initial genetic dissection of the role of specific HDACs in murine models has revealed that inactivation of Hdac1 and Hdac2 results in hematopoietic defects, and gene deletion in established tumor cells results in loss of proliferation and/or decreased survival ${ }^{5,6}$. Indeed, the development of class I (HDACs 1, 2, 3 and 8)-selective HDACi such as the Food and Drug Administration (FDA)-approved compound romidepsin, supports the proposed pro-oncogenic role of class I HDACs ${ }^{7,8}$.

APL is caused by the fusion protein PML-RAR ${ }^{9}$ and expression of PML-RAR in murine hematopoietic progenitors leads to APL that reflects the human disease ${ }^{10}$. Prior to full leukemic transformation PML-RAR induces a "pre-leukemic" stage without an overtly dramatic phenotype that leads to substantial alterations in the selfrenewing properties of the pre-leukemic cells ${ }^{11,12}$. It is assumed therefore that PMLRAR is necessary but not sufficient to cause APL, and additional genetic hits, largely unknown, must occur for the clonal expansion of leukemic blasts.

Different HDAC-containing complexes associate with PML-RAR. These complexes (such as NURD and SMRT/NCoR) include Class I HDACs ${ }^{13}$. Through its association 
From bloodjournal.hematologylibrary.org by Pier Guiseppe Pelicci on March 26, 2013. For personal use only.

with HDACs, PML-RAR is able to transcriptionally silence its target genes and to regulate the stability of the oncosuppressor $\mathrm{p} 53^{14}$. In view of these observations, we functionally assessed the role of individual HDACs, in this case Hdac1/2, in APL development and progression. 


\section{Methods}

\section{Mice}

Transgenic $\mathrm{mCG}^{\mathrm{PR} / \mathrm{PR}}$ mice were generously provided by T.J. Ley (Washington University, St Louis) and backcrossed into the C57BL/6J strain. C57BL/6J p53 ${ }^{-/-}$mice were obtained from the Jackson Laboratory. E $\mu$-myc transgenic mice were kindly provided by Dr Jerry Adams (Walter and Eliza Hall Institute, Melbourne, Australia) ${ }^{15}$. For lin- transplantation experiments, lethally irradiated C57BL/6J mice, 12 to 14 weeks old, were inoculated intravenously with $300.000 \mathrm{GFP}^{+}$-transduced $\operatorname{lin}^{-}$cells, together with 500.000 spleen cells obtained from a WT mouse ${ }^{16}$. For leukemia transplantation, $\mathrm{GFP}^{+}$transduced leukemic cells were injected intravenously $(200.000$ cells/mouse) in syngeneic recipient mice. APL leukemias used for Hdac1 knockdown experiments shown in figure 5 have been described previously ${ }^{16}$. For the generation

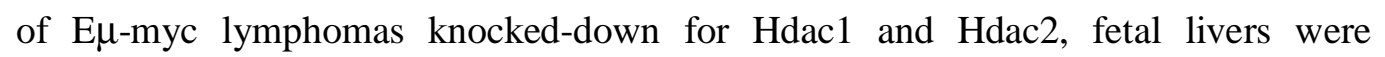
harvested from E13.5-E15.5 E $\mu$-myc embryos (in the C57BL/6/CD45.2 strain) and transduced with pLMSshRNAmiR30.SCR, pLMSshRNAmiR30.Hdac1 or pLMSshRNAmiR30Hdac2 constructs as detailed previously ${ }^{17,18}$. Irradiated recipient PTPRCA/CD 4 5.1 mice ${ }^{19}$ were injected with unsorted fetal liver cells $\left(1 \times 10^{6}\right.$ $\mathrm{GFP}^{+}$per mouse) and sacrificed once lymphoma developed at which point lymph nodes, spleen and thymus were harvested and stored in liquid nitrogen for further analysis. Animals were checked periodically for clinical signs of disease (by inspection, and periodical blood analysis using the AcT ${ }^{\mathrm{TM}}$ 5diff Beckman Coulter, Brea, CA, USA). Long term reconstitution of the hematopoietic compartment was assessed by scoring percentage of $\mathrm{GFP}^{+}$cells in peripheral blood at least four months after transplantation. Mice were sacrificed by $\mathrm{CO}_{2}$ inhalation when they became 
detectably ill. The survival rate was calculated using the Kaplan-Meier method. All procedures involving animals were done in accordance with national and international laws and policies.

\section{Purification of lin- cells and infection procedures}

Lin- cells from WT C57BL/6J or transgenic $\mathrm{mCG}^{\mathrm{PR} / \mathrm{PR}}$ mice and APL blasts from leukemic animals were obtained and maintained as previously described ${ }^{16}$. Cells were infected using the viral supernatants (see below), and then sorted by GFP positivity (FACSAria, Becton Dickinson, Franklin Lakes, NJ, USA ${ }^{16}$ ).

E $\mu$-myc fetal liver cells were grown in high-glucose Dulbecco modified Eagle medium (DMEM) supplemented with $10 \%$ fetal calf serum, penicillin (100 $\mathrm{U} / \mathrm{mL}$ )/streptomycin (100 mg/mL), $0.1 \mathrm{mM}$ L-asparagine, $50 \mathrm{mM}$ 2-mercaptoethanol, recombinant IL-3 (2ng/mL), IL-6 (2ng/mL) and SCF (10ng/mL) (all cytokines from PeproTech).

\section{Retroviral shRNA constructs and virus production}

ShRNA-based retroviral plasmids (used for the experiments with pre-leukemic, leukemic and p53 null cells) were generated by ligating synthetic oligonucleotides targeting the indicated mRNAs into a modified pRETRO-SUPER vector ${ }^{20}$ in which the cDNA for puromycin selection had been replaced with that encoding for EGFP. The shRNA sequences (supplemental Table 4) are in the format: target sequence sense (underlined)-loop-target sequence antisense (underlined).

The pRETRO-SUPER vectors and package plasmid pCL-Eco were co-transfected into packaging ecotropic Phoenix cells, and the viral supernatants were produced as previously described $^{16}$. 
Targeting sequences for shRNA-miR30 constructs (used for the experiments with E $\mu$ myc cells) were identified using the previously described DSIR algorithm ${ }^{21}$. The top ranked short hairpin (shRNAs) were used to create 10 miR30 sequences (97mer, Sigma-Aldrich) and these were cloned into the pLMS vector following generation of approximately $110 \mathrm{bp}$ shRNA-miR30's by amplification of 97mers using 5'mir30Xhol (CAGAAGGCTCGAGAAGgtATATTGCTGTTGACAGTGAGCG) and 5'miR30-EcoRI (CTAAAGTAGCCCCTTGAATTCCGAGGCAGTAGGCA) primers. The miRNA oligomer sequences (supplemental Table 4) are in the format: mir-30 context-sense (underlined)-loop-antisense (underlined). Viral supernatants were produced as previously described ${ }^{17,18}$. Knock-down regulation of gene expression can be associated to experimental artefacts, due to off-target effects ${ }^{22}$. We can exclude that off-target effects confound the interpretation of our results, for the following reasons: a) the use of different sequences to interfere with Hdac1 expression, both in vivo and in vitro, gave identical results; b) the in vitro Hdac1 knock-down phenotype (potentiation of differentiation block and enhancement of colony forming ability) was rescued by re-expressing a non-interferable Hdac1 protein in lin-cells; c) the in vivo pharmacological inhibition of HDACs recapitulates the observed Hdac1 knock-down phenotype.

\section{Cell lines}

Human APL NB4 cells were grown in RPMI supplemented with $10 \%$ fetal bovine serum, 2 mM L-glutamine, and antibiotics. Phoenix cells were purchased from ATCC and maintained in Dulbecco's modified Eagle's medium supplemented with $10 \%$ fetal bovine serum, $2 \mathrm{mM} \mathrm{L-glutamine,} \mathrm{and} \mathrm{antibiotics.} \mathrm{Cultures} \mathrm{were} \mathrm{maintained} \mathrm{in} \mathrm{a}$ humidified tissue culture incubator at $37^{\circ} \mathrm{C}$ in $5 \% \mathrm{CO}_{2}$. 


\section{Immunoblots and Antibodies}

Whole cell extracts were obtained by lysis in SDS buffer (50 mM Tris $\mathrm{HCl}, 10 \%$ glycerol, $2 \%$ SDS). Proteins were separated by SDS-PAGE, blotted onto PVDF membrane and probed with the indicated antibodies. For determination of p53 status of E $\mu$-myc lymphomas, $1.5 \times 10^{6}$ FACS-sorted $\mathrm{GFP}^{+}$tumour cells were exposed to $10 \mathrm{~Gy}$ irradiation and incubated at $37^{\circ} \mathrm{C}$ in $10 \% \mathrm{CO}_{2}$ for 1 hour alongside nonirradiated controls and then lysed. The antibodies used in the study were: anti-Hdac1 (ab7028), anti-Hdac2, (ab7029), anti-HDAC3 (ab7030), anti-H4-Ac K5 (ab51997) and anti-H3 (ab1791) (Abcam, Cambridge, UK); anti-RAR $\alpha$ (sc-551) (Biotechnology Inc., Santa Cruz, CA, USA); anti-Acetylated histone H3 and H4 were detected using a home-made antibody ${ }^{23}$; anti-p53 (Novacastra, NCL-p53-505), anti-p19ARF (Santa Cruz sc32748), anti-Hsp90 (Stressgen ADI-SPA-830) and anti- $\beta$-actin (Sigma Aldrich).

\section{Differentiation, serial replating and cytogenetic assays}

Five thousands sorted lin- cells were plated in methylcellulose medium (MethoCult ${ }^{\mathrm{TM}}$ SF M3236, Stem Cell Technology, Vancouver, BC, Canada) containing 15\% FCS, 2ng/ml IL3, 2ng/ml IL6, 50ng/ml SCF, 60ng/ml G-CSF and 20ng/ml GM-CSF (Peprotech, Rocky Hill, NJ USA). After 7-10 days of culture, colonies were scored and the cells used for immunolabeling, serial replating experiments and morphological analysis ${ }^{16}$. 


\section{Analysis of mitotic chromosome spreads}

Lin- cells were plated in methylcellulose medium as previously described. After 4 days, cells were harvested and resuspended in RPMI medium containing $10 \%$ fetal calf serum, 20ng/ml IL3, 20ng/ml IL6, 100ng/ml SCF and $0.1 \mu \mathrm{g} / \mathrm{ml}$ of colcemid (Gibco, Life Technologies Europe Monza, Italy). After four hours, cells were washed and resuspended in hypotonic buffer $(0,075 \mathrm{M} \mathrm{KCl})$, incubated for $1 \mathrm{hr}$ at $37^{\circ} \mathrm{C}$ and then fixed with methanol/acetone (3:1). Cells were spotted on glass slides and stained with Giemsa (Sigma-Aldrich, St Louis, MO, USA). Metaphases were analyzed by optical microscopy.

\section{In vivo BrdU incorporation}

BrdU incorporation was analyzed by fluorescence-activated cell sorting analysis (BD, FACSCantoII BD, FACSDiva Software V6.1.1, Becton Dickinson, Franklin Lakes, NJ, USA) after four hours of a single intraperitoneal (IP) injection of BrdU (40mg/Kg) using the FITC BrdU Flow Kit (BD).

\section{Immunophenotyping and histopathological analysis}

Fluorescence activated cell sorting (FACS) analysis (BD, FACSCantoII BD, FACSDiva Software V6.1.1) was performed on splenocytes and bone marrow cells derived from transplanted mice. Cells derived from healthy mice were used as control. The antibodies used for the immunophenotyping were: Ly-6A/E (SCA1) PECy5.5 conjugated, CD117 (C-Kit) APC conjugated, anti mouse CD45.2 FITC conjugated, CD11b (MAC1), Ly-6G (Gr-1), CD3e, CD45R (B220) all PE-Cy7 conjugated (eBioscience, San Diego, CA, USA). Blood smears and cytospins were stained using the May-Grünwald-Giemsa method (Sigma-Aldrich). 


\section{Pharmacological treatments}

Preleukemic six-eight weeks old $\mathrm{mCG}^{\mathrm{PR} / \mathrm{PR}}$ mice were intraperitoneally injected with VPA (Sigma) dissolved in PBS at the dose of $400 \mathrm{mg} / \mathrm{kg}$ twice a day for 14 days. For differentiation analysis, twelve hours after the last injection the mice were sacrificed and bone marrow cells were analyzed by FACS for surface differentiation markers or plated in methylcellulose as described. For in vivo experiments, the mice were followed until leukemia development. For APL mice treatment, $2 * 10^{\wedge} 5$ APL cells were injected intravenously into non-irradiated congenic recipient mice (C57Bl/6Ly5.1) and then treated with VPA (intraperitoneally at the dose of $400 \square \mathrm{mg} / \mathrm{kg}$ twice a day for 4 weeks) when the blast cells (Ly5.2) in peripheral blood reached 5-10\% ${ }^{24}$.

\section{Quantitative PCR}

Total RNA was purified using RNeasy Mini Kit (Qiagen, Valencia, CA), quantified and reverse transcribed. Five-ten ng of cDNA were used to perform quantitative PCR (qPCR) using SYBR Green Reaction Mix (Perkin Elmer, Boston, MA). mRNA levels were normalized against GAPDH mRNA. The sequences of the primers used in this study are listed in supplemental Table 4.

\section{Statistical Analysis}

Statistical analyses were performed using unpaired samples two tails $t$ test (Graphpad software) unless otherwise specified. Statistical analysis of the Kaplan-Meier survival curves were done using the logrank test (Prism 4.0 software). 


\section{Results}

\section{Hdac1/ Hdac2 knock-down accelerates APL development}

As a model system for PML-RAR-driven APL we used the well-characterized $\mathrm{mCG}^{\mathrm{PR} / \mathrm{PR}}$ mouse model $^{12}$. Lineage-negative (lin') cells enriched in hematopoietic stem cells (HSCs) and progenitors from $\mathrm{mCG}^{\mathrm{PR} / \mathrm{PR}}$ mice ${ }^{16}$ were transduced with GFPtagged retroviral vectors targeting Hdac1 or the control (CTRL) firefly luciferase transcripts. FACS-purified $\mathrm{GFP}^{+} / \mathrm{lin}^{-}$cells were then analyzed in vitro and in vivo (supplemental Figure 1). RNA and protein analysis confirmed a strong reduction of Hdac1 by the targeting shRNA constructs (Figure 1A, supplemental Figure 2) with a compensatory increase in the expression of Hdac2 but not Hdac3 (Figure 1A) as previously reported $^{6,25}$. In addition, we observed increased acetylation of histone H4 at lysine 5 , that is preferentially de-acetylated by $\operatorname{Hdac}^{25,26}$, while global histone acetylation remained relatively unchanged (Figure 1A). Knock-down of Hdac1 had no effect on the expression of PML-RAR (supplemental Figures 3, 4).

Reconstitution of irradiated syngeneic recipient mice with $\mathrm{GFP}^{+} / \mathrm{lin}^{-} / \mathrm{Hdac} 1$ knockdown (Hdac1-kd) cells led to a dramatic shortening of leukemia onset compared to controls (Figures 1B, supplemental Table 1A) and knock-down of Hdac1 was maintained in leukemias derived from these mice (Figures 1C, supplemental Figure 5). Interestingly, the up-regulation of Hdac2 observed in freshly transduced cells was not maintained in leukemic blasts (Figure 1C). CTRL and Hdac1-kd leukemias were essentially indistinguishable macroscopically, histologically and cytologically (Figure 1D, supplemental Figures 6A-B). In contrast, immunophenotypic analysis revealed a greater proportion of immature $\mathrm{Gr}-1^{+} / \mathrm{c}-\mathrm{Kit}^{+} / \mathrm{Hdac} 1-\mathrm{kd}$ cells (Figure 1E, supplemental Table 2). Transplantation of primary Hdac1-kd or CTRL APLs into syngeneic 
recipients resulted in the development of secondary leukemias at similar rates (supplemental Figure 7) indicating that Hdac1 knock-down mainly affects the preleukemic stage.

Similar studies were performed using shRNA vectors targeting Hdac2. Western blot analysis of transduced $\mathrm{GFP}^{+} / \mathrm{lin}^{-} / \mathrm{Hdac} 2-\mathrm{kd}$ cells confirmed decreased Hdac2 expression with little concomitant increase in Hdac1 levels, suggesting that the modality of regulation of Hdac1 and Hdac2 differs (supplemental Figure 8A). Knockdown of Hdac2 led to a significant acceleration of APL development (supplemental Figure 8B), though less pronounced than Hdac1 knock-down (supplemental Figure 8C) and APL cells from these mice maintained decreased Hdac2 expression (supplemental Figure 8D). Interestingly, while Hdac1 levels were generally unchanged, in one case (n. 10) we observed a strong reduction of Hdac1 levels in leukemic cells, hinting at a potentially cooperating oncosuppressive role for Hdac1 and Hdac2 (supplemental Figure 8D).

Expression analysis of a collection of primary human APL samples and controls normal $\mathrm{CD}_{3} 4^{+}$progenitor cells showed that Hdac1 and Hdac2 transcript levels were reduced in APL (supplemental Figures 9A-B). To further validate this observation, we surveyed the expression levels of Hdac1 and Hdac2 in primary human AML samples from available gene profiling datasets ${ }^{27}$. Interestingly, Hdac1 mRNA levels were selectively reduced in primary APL samples, compared to other AML subtypes, and relative to normal progenitor $\mathrm{CD} 34^{+}$cells and normal promyelocytes (supplemental Figure 9C). Hdac2 levels were also down-regulated compared to normal CD $34^{+}$cells in several AML subtypes, though during normal myeloid differentiation there is a strong decrease in expression in promyelocytes (supplemental Figure 9D). 
Collectively, these results support a potential oncosuppressor role, at least of Hdac1, in human APL.

\section{Hdac1 behaves as a general oncosuppressor}

To determine if accelerated tumorigenesis following knock-down of Hdacs 1 or 2 was restricted to APL, we performed additional knock-down experiments in two different murine lymphoma models. We firstly examined the role of Hdac1 and 2 on spontaneous lymphomogenesis occurring in $\mathrm{p}^{-3^{--}}$mice ${ }^{28}$. After transduction with the Hdac1- or 2-targeting vectors, lin $^{-}$cells derived from $\mathrm{p} 53^{-/-}$mice were transplanted into syngeneic, lethally irradiated mice (Figure 2A-B). All transplanted animals developed thymic lymphomas, and knock-down of Hdac1 significantly accelerated lymphomagenesis (Figure 2B left panel, supplemental Table 1B). Hdac2 knock-down, in contrast, did not result in a significant change in survival of the mice (Figure 2B right panel, supplemental Table 1B), suggesting that the oncosuppressive functions of Hdac1 and Hdac2 may be context-dependent.

We then investigated a role for Hdac1 and 2 in the context of c-myc overexpression utilizing the $\mathrm{E} \mu$-myc mouse ${ }^{15}$. E $\mu$-myc fetal liver hematopoietic progenitor cells were transduced with retroviruses expressing shRNAs targeting Hdacs 1 or 2. Unsorted cells were transplanted into irradiated recipient mice and tumor development was monitored (Figure 2C, supplemental Table 1C). Consistent with the data outlined above, knock-down of Hdac1 hastened the rate of myc-induced lymphomagenesis while the effects of Hdac2 knockdown was considerably more modest and did not achieve statistical significance (Figure $2 \mathrm{C}$, supplemental Table $1 \mathrm{C}$ ). $\mathrm{GFP}^{+}$tumors isolated from $\mathrm{E} \mu-\mathrm{myc} / \mathrm{Hdac} 1-\mathrm{kd}$ and $\mathrm{E} \mu-\mathrm{myc} / \mathrm{Hdac} 2-\mathrm{kd}$ mice showed robust and specific knock-down of the targeted protein (Figure 2D). Moreover, we tested these 
tumors for maintenance of a p53 response and observed the p53 pathway to be functionally intact as demonstrated by $\gamma$-irradiation-induced upregulation of p53 and constitutively low expression of $\mathrm{p} 19^{\mathrm{ARF}}$ which is utilised as surrogate marker for wild type p53 expression in this model ${ }^{29}$ (supplemental Figure 10). Finally, sequence

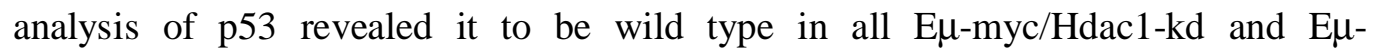
myc/Hdac2-kd tumors (data not shown). These data suggest that E $\mu$-myc tumors with loss of Hdac1 or 2 develop in a manner that maintains expression of wild type p53. Taken together, these data extend our initial findings in APL, and indicate a more general oncosuppressive role for Hdac1.

\section{Hdac1 knock-down enhances differentiation block and genomic instability of PML-RAR expressing cells}

APL is characterized by a block in myeloid differentiation and alteration of genomic stability $^{30,31}$. Both events are supposedly driven by the direct action of PML-RAR, and at least in part this is due to its association with Hdacs ${ }^{32}$, although Hdacs can affect both biological processes independently of PML-RAR ${ }^{33,34}$. We therefore investigated whether Hdac1 knock-down affected either or both of these processes in the pre-leukemic setting to accelerate PML-RAR-driven APL. As previously shown $^{16,35}$, expression of PML-RAR in the pre-leukemic phase caused a modest defect on differentiation in vitro (supplemental Figure 11), and Hdac1 knock-down greatly augmented this effect with a strong decrease of Mac- $1^{+}$cells, and an increase of c-Kit ${ }^{+}$, immature cells (Figure 3A-B). Interestingly, this phenomenon was PMLRAR-dependent, since Hdac1 knock-down in wild-type lin cells did not significantly affect differentiation (supplemental Figure 12). PML-RAR expression results in an enhanced proliferative ability of $\operatorname{lin}^{-}$cells ${ }^{35}$ and consistent with the observed 
potentiation of the differentiation block, Hdac1 knock-down led to a further increase in the proliferative potential of PML-RAR expressing lin cells, as demonstrated by the higher number of colonies recovered in serial re-plating experiments (Figure 3C). We next determined the effect of Hdac1 knock-down on genomic stability. Colony forming assays with $\mathrm{GFP}^{+} /$lin $^{-}$cells confirmed previous studies ${ }^{36}$ demonstrating that PML-RAR expression enhanced genome instability compared to wild-type cells (supplemental Figure 13). Hdac1 knock-down amplified this phenomenon with more than $50 \%$ of metaphases being aneuploid after in vitro plating (Figure 3D).

To confirm the specificity of the Hdac1 knock-down effects, PML-RAR-expressing lin/Hdac1-kd cells were super-infected with a retrovirus expressing Hdac1 cDNA that could not be targeted by the RNAi knock-down constructs (supplemental Figure 14A). Strikingly, expression of non-targetable Hdac1 essentially abolished the differentiation block observed upon Hdac1 knock-down, confirming that the observed phenotype was due to the selective loss of the protein (supplemental Figure 14B-C). Taken together, these results indicate that down-regulation of Hdac1 potentiates the effects of PML-RAR on differentiation and genomic stability of hematopoietic progenitors, consistent with the observed acceleration of leukemogenesis in vivo.

\section{Hdac1 knock-down primes the expansion of the prospective leukemic initiating cell compartment at the pre-leukemic stage}

To determine the effect of Hdac1 knock-down on the differentiation of pre-leukemic myeloid cells in vivo, irradiated recipient mice were reconstituted with PML-RARexpressing $\mathrm{GFP}^{+} / \mathrm{lin}^{-} / \mathrm{Hdac} 1-\mathrm{kd}$ and $\mathrm{GFP}^{+} / \mathrm{lin}^{-} / \mathrm{CTRL}$ cells, and bone marrows from transplanted mice were analysed at different time points during the pre-leukemic phase (supplemental Figure 15). Knock-down of Hdac1 caused a dramatic expansion 
of immature $\mathrm{Gr}-1^{+} / \mathrm{c}-\mathrm{Kit}^{+}$cells and a decrease in expression of Mac-1 (Figure 4A-B). As a consequence of the expansion of $\mathrm{Gr}-1^{+} / \mathrm{c}-\mathrm{Kit}^{+} / \mathrm{Mac}-1^{\text {low }}$ cells, we observed an imbalance in lineage distribution following knock-down of Hdac1 in pre-leukemic APL mice, with a shift towards the myeloid lineage at the expense of the lymphoid compartment (Figure 4A, supplemental Table 3). Consistent with their expansion, the proliferative ability in vivo of PML-RAR-expressing $\mathrm{Gr}-1^{+} / \mathrm{c}-\mathrm{Kit}{ }^{+} / \mathrm{Hdac} 1-\mathrm{kd}$ cells was strongly enhanced compared to CTRL cells as assessed by BrdU incorporation (Figure 4C). This effect was confirmed in vitro, as shown by the increase in colony forming cells in serial methylcellulose assays (Figure 4D). In addition, when cultured in methylcellulose supplemented with a pro-differentiation cytokine cocktail, PMLRAR expressing $\mathrm{Gr}-1^{+} / \mathrm{c}-\mathrm{Kit}^{+} / \mathrm{Hdac} 1-\mathrm{kd}$ cells maintained their undifferentiated phenotype which lasted for several platings, while PML-RAR-expressing CTRL cells showed an activated differentiation program (Figure 4E). Intriguingly, in frankly leukemic mice it has been shown that the leukemic stem cell compartment is enriched in $\mathrm{Gr}-1^{+} / \mathrm{c}-\mathrm{Kit}^{+}$cells ${ }^{37,38}$. We therefore transplanted PML-RAR-expressing Gr- $1^{+} / \mathrm{c}-$ $\mathrm{Kit}^{+} / \mathrm{Hdac} 1-\mathrm{kd}$ cells from pre-leukemic mice into secondary recipient mice, which developed APL (supplemental Figure 16). Taken together, these results show that during the pre-leukemic stage Hdac1 functions to prevent the expansion of a PMLRAR-expressing cell sub-population prototypic of the leukemic stem cell compartment in the leukemic stage, that is able to give rise to APL.

\section{Hdac1 knock-down has an antitumor activity on APL cells at the leukemic stage}

Our results are apparently at odds with the known anti-tumor effects of HDACi, shown in several contexts, including leukemias expressing the PML-RAR oncoprotein $^{30}$. We therefore knocked-down Hdac1 (or luciferase as a control: CTRL) 
in frankly leukemic APL cells ${ }^{16}$ (Figure 5A-B) and observed concomitant induction of Hdac2 expression and increased histone acetylation (Figure 5B). GFP ${ }^{+} / \mathrm{Hdac} 1-\mathrm{kd}$ and $\mathrm{GFP}^{+} / \mathrm{CTRL}$ APL cells were transplanted into syngeneic recipient mice and in contrast to the accelerated tumorigenesis observed following knock-down of Hdac1 in pre-leukemic cells, Hdac1 depletion caused an increased overall survival of the recipient mice (Figure 5C). Consistent with this result and as previously observed ${ }^{24,30}$, treatment with the class I HDAC inhibitor Valproic acid (VPA) ${ }^{39,40}$ caused an increased overall survival of frankly leukemic APL mice (Figure 5D and supplemental Figure 17).

These results suggest that Hdac1 activity plays opposing roles at different stages of APL development: it antagonizes the oncogenic activity of PML-RAR at the preleukemic stage, while favouring the growth of the leukemic mass in the overt leukemic state.

\section{Pharmacological inhibition of class I HDACs mimics the phenotype of Hdac1}

\section{knock-down}

We then determined if the biological effect of Hdac1 knock-down in PML-RARexpressing pre-leukemic cells could be phenocopied by inhibiting HDACs pharmacologically. Strikingly, short-term treatment with VPA doubled the number of $\mathrm{Gr}-1^{+} / \mathrm{c}-\mathrm{Kit}^{+}$cells in the bone marrow of pre-leukemic mice (Figure 6A, left panel). Bone marrow cells derived from VPA-treated mice gave rise to a higher number of colonies than cells derived from untreated mice (Figure 6A, right panel). Importantly, VPA-treated mice developed leukemia within a shorter period compared to untreated mice (Figure 6C, supplemental Table 1D). Taken together, these results show that 
pharmacological inhibition of HDAC enzymatic activity in pre-leukemic mice mimics the oncogenic effects of Hdac1 knock-down.

\section{Discussion}

Here, we show in different mouse tumor models (APL, p53 $3^{--}$and myc-driven lymphomas) that one putative barrier to full transformation is surprisingly provided by class I Hdacs 1 and 2. Knock-down of Hdac1 potentiated both the block of cellular differentiation, and the increased genomic instability mediated by PML-RAR in hematopoietic progenitors. Either or both biological deregulations could be sufficient to cooperate with the tumor-promoting activities of oncoproteins such as PML-RAR and Myc and would provide a functional explanation for the observed increase in frequency of transformation to full leukemia in Hdac1-deficient cells. Additionally, and potentially linked to those events, we observed in Hdac1-deficient pre-leukemic cells a dramatic expansion of a subpopulation of myeloid precursor cells $\left(\mathrm{Gr}^{+}\right.$and c$\mathrm{Kit}^{+}$cells) that represents the major source of leukemic stem cells in the full leukemic stage $^{37,38}$. We hypothesize that in pre-leukemia this subpopulation acts as a reservoir of target cells for full leukemic transformation: in the presence of decreased levels of Hdac1, expansion of $\mathrm{Gr}^{+} / \mathrm{c}-\mathrm{Kit}^{+}$cells leads to an increase in the number of candidate target cells and of the probability of transformation, thus accelerating leukemogenesis. These results are reminiscent of the role of histone H3K9 methylation in the tumor-suppression of Ras and myc-driven lymphoma development in transgenic mice ${ }^{41}$, and support an important role for heterochromatin as a tumor suppressive mechanism ${ }^{41-43}$. Consistent with the notion that HDACs can function as tumor suppressors, Hdac1 and Hdac2 mRNA levels were found to be selectively reduced in human AML samples, suggesting that this function may be important in human leukemogenesis. 
HDACs have been widely considered to have tumor-promoting and/or sustaining roles especially given the impressive anti-tumor responses mediated by HDACi in certain hematological malignancies ${ }^{7}$. Indeed, combined genetic deletion of Hdac1 and Hdac2 results in the activation of a senescent program, and/or mitotic catastrophe and death of transformed cells 5 . Here, we showed that knock-down of Hdac1 in transplanted PML-RAR-expressing leukemia cells prolonged the survival of recipient mice, supporting the view that Hdac1 has oncogenic activity in established tumor cells. As a potential explanation to reconcile the opposing roles of Hdac1 unraveled in APL, we speculate that Hdac1 may have distinct functions in different leukemia subpopulations: indeed, VPA treatment induces differentiation and death of APL blasts, sparing the leukemic stem cell compartment. ${ }^{24}$

Short-term in vivo treatment of pre-leukemic mice with the class I HDACi VPA phenocopied the effect of Hdac1 knock-down during PML-RAR-mediated leukemogenesis with expansion of $\mathrm{Gr}^{+} / \mathrm{c}-\mathrm{Kit}^{+}$population and accelerated disease. Intriguingly, this phenomenon was not observed following treatment of pre-malignant E $\mu$-myc mice with VPA, indicating that a tumor-type or oncogene-specific effect may be at play (data not shown). Nevertheless, these results are somewhat unsettling concerning the growing clinical use of HDACi. The broad inhibition of multiple HDACs by most available HDACi has been proposed as a potential explanation for the lack of sustained efficacy of these agents in most cancer patients. Our data suggest that HDAC inhibition may block intrinsic anti-tumor functions of HDACs, and imply that more studies are needed to systematically dissect the role of individual HDACs, at different stages of tumorigenesis, in different tumor compartments and in different tumor cell types. 


\section{Acknowledgements}

Work is SM's lab is supported by AIRC (Italian Association for Cancer Research), FIRC (Italian Foundation for Cancer Research), CNR (National Research Council) Flagship Project Epigen, MIUR and MIS (Ministery of Health and Research), European Community (FP7 Blueprint and 4D Projects).

RWJ is a Principal Research Fellow of the National Health and Medical Research Council of Australia (NHMRC) and supported by NHMRC Program and Project Grants, Cancer Council Victoria, The Leukemia Foundation of Australia, Victorian Breast Cancer Research Consortium and the Victorian Cancer Agency. We thank: Simona Ronzoni, Anna Sciullo, Ivan Muradore, Mario Faretta, Gabriele Bucci for technical assistance; Daniela Bossi, Chiara Ronchini for helpful discussion; Simona Citro for the HDAC1 expression plasmid.

\section{Authorship}

Contribution: F.S. and O.A.B. designed and performed experiments and assisted in writing the manuscript; G.M.M., L.C., performed experiments and provided discussion; R. D., I. P., S.S., I.B., and L.F., provided discussion and technical advice; L.A., P. P., S.C., provided significant discussion; S.M. and R.W.J. designed experiments, provided discussion, and assisted in writing the manuscript

Conflict-of-interest disclosure: The authors declare no competing financial interests. 
From bloodjournal.hematologylibrary.org by Pier Guiseppe Pelicci on March 26, 2013. For personal use only.

Correspondence: Saverio Minucci, Department of Experimental Oncology, European Institute of Oncology, IFOM-IEO Campus, via Adamello 16, 20139 Milan, Italy. Email: saverio.minucci@ieo.eu, phone: +390257489832, fax: +390294375990. Ricky Johnstone, Peter MacCallum Cancer Centre, St Andrews Place, East Melbourne 3002, Victoria, Australia, Email: ricky.johnstone@ petermac.org, phone: +61 396563727, fax: +61396561411. 


\section{References}

1. Jones PA, Baylin SB. The epigenomics of cancer. Cell. 2007;128(4):683-692.

2. Botrugno OA, Santoro F, Minucci S. Histone deacetylase inhibitors as a new weapon in the arsenal of differentiation therapies of cancer. Cancer Lett. 2009;280(2):134-144.

3. Haberland M, Montgomery RL, Olson EN. The many roles of histone deacetylases in development and physiology: implications for disease and therapy. Nat Rev Genet. 2009;10(1):32-42.

4. Yang XJ, Seto E. The Rpd3/Hda1 family of lysine deacetylases: from bacteria and yeast to mice and men. Nat Rev Mol Cell Biol. 2008;9(3):206-218.

5. Haberland M, Johnson A, Mokalled MH, Montgomery RL, Olson EN. Genetic dissection of histone deacetylase requirement in tumor cells. Proc Natl Acad Sci U S A. 2009;106(19):7751-7755.

6. Wilting RH, Yanover E, Heideman MR, et al. Overlapping functions of Hdac1 and Hdac2 in cell cycle regulation and haematopoiesis. EMBO J. 2010;29(15):25862597.

7. Bolden JE, Peart MJ, Johnstone RW. Anticancer activities of histone deacetylase inhibitors. Nat Rev Drug Discov. 2006;5(9):769-784.

8. Mercurio C, Minucci S, Pelicci PG. Histone deacetylases and epigenetic therapies of hematological malignancies. Pharmacol Res. 2010;62(1):18-34.

9. de The H, Chen Z. Acute promyelocytic leukaemia: novel insights into the mechanisms of cure. Nat Rev Cancer. 2010;10(11):775-783.

10. Lallemand-Breitenbach V, Zhu J, Kogan S, Chen Z, de The H. Opinion: how patients have benefited from mouse models of acute promyelocytic leukaemia. Nat Rev Cancer. 2005;5(10):821-827.

11. Welch JS, Yuan W, Ley TJ. PML-RARA can increase hematopoietic selfrenewal without causing a myeloproliferative disease in mice. $J$ Clin Invest. 2011;121(4):1636-1645.

12. Westervelt P, Lane AA, Pollock JL, et al. High-penetrance mouse model of acute promyelocytic leukemia with very low levels of PML-RARalpha expression. Blood. 2003;102(5):1857-1865.

13. Morey L, Brenner C, Fazi F, et al. MBD3, a component of the NuRD complex, facilitates chromatin alteration and deposition of epigenetic marks. Mol Cell Biol. 2008;28(19):5912-5923. 
14. Insinga A, Monestiroli S, Ronzoni S, et al. Impairment of p53 acetylation, stability and function by an oncogenic transcription factor. EMBO J. 2004;23(5):1144-1154.

15. Adams JM, Harris AW, Pinkert CA, et al. The c-myc oncogene driven by immunoglobulin enhancers induces lymphoid malignancy in transgenic mice. Nature. 1985;318(6046):533-538.

16. Minucci S, Monestiroli S, Giavara S, et al. PML-RAR induces promyelocytic leukemias with high efficiency following retroviral gene transfer into purified murine hematopoietic progenitors. Blood. 2002;100(8):2989-2995.

17. Dickins RA, Hemann MT, Zilfou JT, et al. Probing tumor phenotypes using stable and regulated synthetic microRNA precursors. Nature genetics. 2005;37(11):1289-1295.

18. Whitecross KF, Alsop AE, Cluse LA, et al. Defining the target specificity of ABT-737 and synergistic antitumor activities in combination with histone deacetylase inhibitors. Blood. 2009;113(9):1982-1991.

19. Michalova J, Savvulidi F, Sefc L, Faltusova K, Forgacova K, Necas E. Hematopoietic stem cells survive circulation arrest and reconstitute hematopoiesis in myeloablated mice. Biology of blood and marrow transplantation: Journal of the American Society for Blood and Marrow Transplantation. 2011;17(9):1273-1281.

20. Brummelkamp TR, Bernards R, Agami R. A system for stable expression of short interfering RNAs in mammalian cells. Science. 2002;296(5567):550-553.

21. Vert JP, Foveau N, Lajaunie C, Vandenbrouck Y. An accurate and interpretable model for siRNA efficacy prediction. BMC Bioinformatics. 2006;7:520.

22. Echeverri CJ, Beachy PA, Baum B, et al. Minimizing the risk of reporting false positives in large-scale RNAi screens. Nat Methods. 2006;3(10):777-779.

23. Ronzoni S, Faretta M, Ballarini M, Pelicci P, Minucci S. New method to detect histone acetylation levels by flow cytometry. Cytometry A. 2005;66(1):52-61.

24. Leiva M, Moretti S, Soilihi H, et al. Valproic acid induces differentiation and transient tumor regression, but spares leukemia-initiating activity in mouse models of APL. Leukemia. 2012;26(7):1630-7.

25. Lagger G, O'Carroll D, Rembold M, et al. Essential function of histone deacetylase 1 in proliferation control and CDK inhibitor repression. EMBO J. 2002;21(11):2672-2681.

26. Lee AY, Paweletz CP, Pollock RM, et al. Quantitative analysis of histone deacetylase-1 selective histone modifications by differential mass spectrometry. $J$ Proteome Res. 2008;7(12):5177-5186. 
27. Payton JE, Grieselhuber NR, Chang LW, et al. High throughput digital quantification of mRNA abundance in primary human acute myeloid leukemia samples. J Clin Invest. 2009;119(6):1714-1726.

28. Donehower LA, Harvey M, Slagle BL, et al. Mice deficient for p53 are developmentally normal but susceptible to spontaneous tumours. Nature. 1992;356(6366):215-221.

29. Wiegmans AP, Alsop AE, Bots M, et al. Deciphering the molecular events necessary for synergistic tumor cell apoptosis mediated by the histone deacetylase inhibitor vorinostat and the BH3 mimetic ABT-737. Cancer research. 2011;71(10):3603-3615.

30. Insinga A, Monestiroli S, Ronzoni S, et al. Inhibitors of histone deacetylases induce tumor-selective apoptosis through activation of the death receptor pathway. Nat Med. 2005;11(1):71-76.

31. Zhong S, Hu P, Ye TZ, Stan R, Ellis NA, Pandolfi PP. A role for PML and the nuclear body in genomic stability. Oncogene. 1999;18(56):7941-7947.

32. Minucci S, Pelicci PG. Histone deacetylase inhibitors and the promise of epigenetic (and more) treatments for cancer. Nat Rev Cancer. 2006;6(1):38-51.

33. Eot-Houllier G, Fulcrand G, Magnaghi-Jaulin L, Jaulin C. Histone deacetylase inhibitors and genomic instability. Cancer Lett. 2009;274(2):169-176.

34. Robert T, Vanoli F, Chiolo I, et al. HDACs link the DNA damage response, processing of double-strand breaks and autophagy. Nature. 2011;471(7336):74-79.

35. Occhionorelli M, Santoro F, Pallavicini I, et al. The self-association coiledcoil domain of PML is sufficient for the oncogenic conversion of the retinoic acid receptor (RAR) alpha. Leukemia. 2011;25(5):814-820.

36. Zimonjic DB, Pollock JL, Westervelt P, Popescu NC, Ley TJ. Acquired, nonrandom chromosomal abnormalities associated with the development of acute promyelocytic leukemia in transgenic mice. Proc Natl Acad Sci $U$ A A. 2000;97(24):13306-13311.

37. Guibal FC, Alberich-Jorda M, Hirai H, et al. Identification of a myeloid committed progenitor as the cancer-initiating cell in acute promyelocytic leukemia. Blood. 2009;114(27):5415-5425.

38. Wojiski S, Guibal FC, Kindler T, et al. PML-RARalpha initiates leukemia by conferring properties of self-renewal to committed promyelocytic progenitors. Leukemia. 2009;23(8):1462-1471.

39. Bantscheff M, Hopf C, Savitski MM, et al. Chemoproteomics profiling of HDAC inhibitors reveals selective targeting of HDAC complexes. Nat Biotechnol. 2011;29(3):255-265. 
40. Khan N, Jeffers M, Kumar S, et al. Determination of the class and isoform selectivity of small-molecule histone deacetylase inhibitors. Biochem J. 2008;409(2):581-589.

41. Braig M, Lee S, Loddenkemper C, et al. Oncogene-induced senescence as an initial barrier in lymphoma development. Nature. 2005;436(7051):660-665.

42. Di Micco R, Sulli G, Dobreva M, et al. Interplay between oncogene-induced DNA damage response and heterochromatin in senescence and cancer. Nat Cell Biol. 2011;13(3):292-302.

43. Reimann M, Lee S, Loddenkemper C, et al. Tumor stroma-derived TGF-beta limits myc-driven lymphomagenesis via Suv39h1-dependent senescence. Cancer Cell. 2010;17(3):262-272. 


\section{Figure legends}

\section{Figure 1: Hdac1 knock-down accelerates APL development.}

A) Immunoblot analysis of Hdac1, 2 and 3 expression, and histone $\mathrm{H} 3 / \mathrm{H} 4$ acetylation in $\mathrm{GFP}^{+}$lin- cells derived from $\mathrm{mCG}^{\mathrm{PR} / \mathrm{PR}}$ mice and transduced with the indicated retroviral vectors. Total histone $\mathrm{H} 3$ served as loading control. B) Leukemia-free survival curves of mice transplanted with the indicated $\mathrm{GFP}^{+}$lin- cells. HDAC1-KDA and HDAC1-KDB indicate two different shRNA against Hdac1 (supplemental Table 4). CTRL vs Hdac1: p<0.0001. C) Hdac1, Hdac2 and Hdac3 expression in bone marrows of leukemic mice. Vinculin was used as loading control. D) Cytological analysis of APL blasts from spleens of moribund animals. Original magnification 1000X, May Grunwal-Giemsa staining, Olympus BX51 E) Representative immunophenotype of leukemic cells derived from spleens of moribund animals.

\section{Figure 2: Hdac1/2 knock-down accelerates lymphomagenesis.}

A-B) Lin $^{-}$cells from $\mathrm{p} 53^{-/-}$mice transduced with the control vector (CTRL) or vectors carrying a shRNA against Hdac1 or Hdac2 were sorted for GFP positivity and injected into lethally irradiated recipient WT mice. A) Immunoblot analysis of cells transduced with the indicated retroviral vectors. The arrow indicates HDAC2. The asterisk indicates HDAC1 residual staining from the previous immunoblotting assay. Hdac3 served as loading control. B) Leukemia-free survival curves of mice transplanted with p53 null lin- cells transduced with the control vector (CTRL) or a vector carrying a shRNA against Hdac1 (left panel, p<0.05) or Hdac2 (right panel, $\mathrm{p}=\mathrm{ns}$ ). C-D) E $\mu$-myc fetal liver progenitor cells were transduced with the control vector (CTRL) or vectors carrying a shRNA against Hdac1 or Hdac2 and injected into 
irradiated recipient PTPRCA mice. C) Kaplan-Meier survival curves are shown; hdac1 $\mathrm{p}<0.05$, hdac2 $\mathrm{p}=\mathrm{ns}$. D) Western blots were performed on FACS sorted $\mathrm{GFP}^{+}$ cell lysates from a control spontaneous E $\mu$-myc lymphoma (lane 1) and the indicated primary lymphomas with knockdown of HDAC1 (lanes 2 and 3) or HDAC2 (lanes 4-6) and analyzed for the expression of the indicated HDACs. B-actin was used as loading control.

Figure 3. Hdac1 knock-down enhances the myeloid differentiation block and genomic instability imposed by PML-RAR in lin- cells derived from $\mathrm{mCG}^{\mathrm{PR} / \mathrm{PR}}$ mice.

Lin- cells were transduced with the indicated vectors, sorted for GFP positivity, and plated in methylcellulose-containing medium. A-B) Analysis of the expression of the indicated differentiation markers in control and Hdac1 knock-down pre-leukemic cells. A representative dot plot (A) and the statistical analysis of 3 independent experiments (B) are shown. C) Analysis of the proliferative potential of control and Hdac1 knock-down pre-leukemic cells by serial replating assay. D) Plot of the percentages of aneuploid and diploid cells in methaphase spreads from CTRL $(n=82)$ and HDAC1-KD ( $\mathrm{n}=76)$ cells. The statistical analysis was performed by Fisher's exact test (GraphPad software).

Figure 4. Hdac1 knock-down primes the expansion of $\mathrm{Gr}-1^{+} / \mathrm{c}-\mathrm{Kit}^{+}$cells in vivo. Lin- cells derived from $\mathrm{mCG}^{\mathrm{PR} / \mathrm{PR}}$ transgenic mice were transduced with the indicated vectors, and sorted $\mathrm{GFP}^{+}$cells were injected into lethally irradiated mice. Mice were sacrificed 30 days post transplantation, and their phenotype was analyzed. A) A representative dot plot showing the levels of the indicated differentiation markers in 
bone marrow cells. Insets show the cytological analysis of the sorted subpopulations (red squares). B) Plot of the levels of $\mathrm{Gr}-1^{+} / \mathrm{c}-\mathrm{Kit}^{+}$cells in the indicated murine bone marrow samples. C) Mice transplanted with the indicated cells were injected with BrdU. In the graph, the levels of BrdU incorporation are shown. D) The indicated Gr$1^{+} / \mathrm{c}-\mathrm{Kit}^{+}$cells were plated in methylcellulose medium and scored for colony forming ability. In the graph, the mean and standard deviation of 3 independent experiments are shown. E) Morphological analysis of the indicated $\mathrm{Gr}-1^{+} / \mathrm{c}-\mathrm{Kit}^{+}$cells, harvested after plating in methylcellulose medium. Left panels, representative cytospins; right panel, percentage of mature and immature cells, original magnification 1000X, May Grunwal-Giemsa staining, Olympus BX51. Statistical analysis was performed using Fisher's exact test.

\section{Figure 5. Hdac1 knock-down in APL blasts increases mice survival.}

A-C) APL blasts from 129sv mice were trandusced with the indicated vectors, sorted for GFP positivity and tranplanted in wt mice. A) Analysis of Hdac1 mRNA levels in APL blasts transduced with the indicated retroviral vectors. Values are normalized against GAPDH and referred to CTRL. The graph represents the average and standard deviation of three independent experiments. B) Immunoblot analysis of the expression of Hdac1, 2 and 3 and histone $\mathrm{H} 3$ acetylation in $\mathrm{GFP}^{+}$APL blasts transduced as indicated. Histone H3 served as loading control. C) Leukemia-free survival curves of mice transplanted with APL blasts transduced with the indicated vectors, and then sorted for GFP expression (CTRL vs HDAC1-KDA or CTRL vs HDAC1-KDB: $\mathrm{p}<0.05$ ). D) Leukemia-free survival curves of C57Bl/6-Ly5.1 recipient mice transplanted with APL cells derived from the $\mathrm{mCG}^{\mathrm{PR} / \mathrm{PR}}$ leukemic mouse \#1.VPA 
treatment was started when the blast cells in peripheral blood reached 5-10\%. CTRL vs VPA: $\mathrm{p}<0.001$. Day 0 indicates the start of the treatment.

Figure 6: VPA treatment mimics the phenotype of Hdac1 knock-down in vivo.

$\mathrm{mCG}^{\mathrm{PR} / \mathrm{PR}}$ mice were treated with VPA or PBS (CTRL) for 14 days and then $\mathrm{A}$ ) twelve hours after the last injection, mice were sacrificed, bone marrows collected and analysed for the expression of Gr-1 and c-Kit (left panel), or colony forming ability (right panel)., or B) followed for leukemia development. In the graph, leukemia-free survival curves from VPA and PBS treated mice; $p<0.05$. 


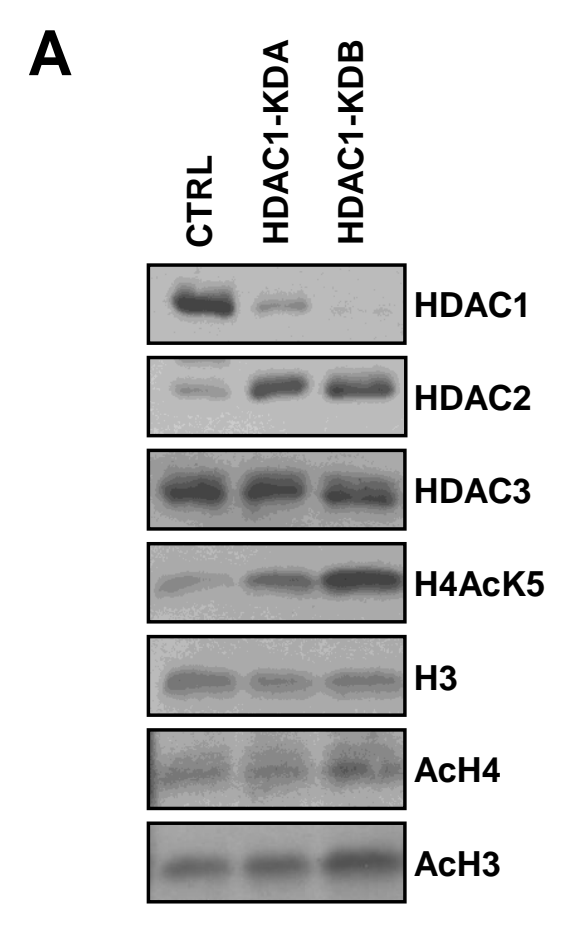

B

D
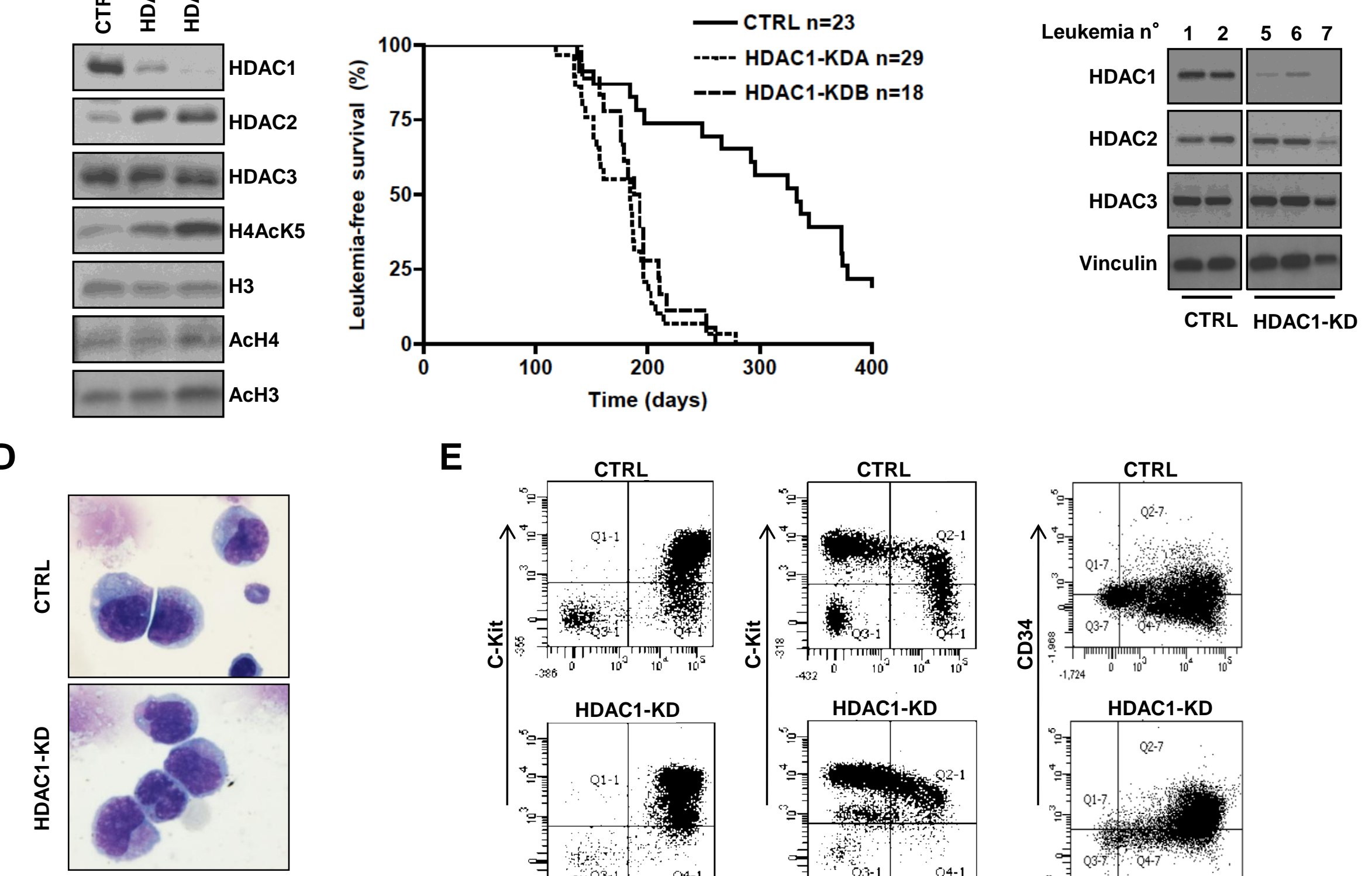

E
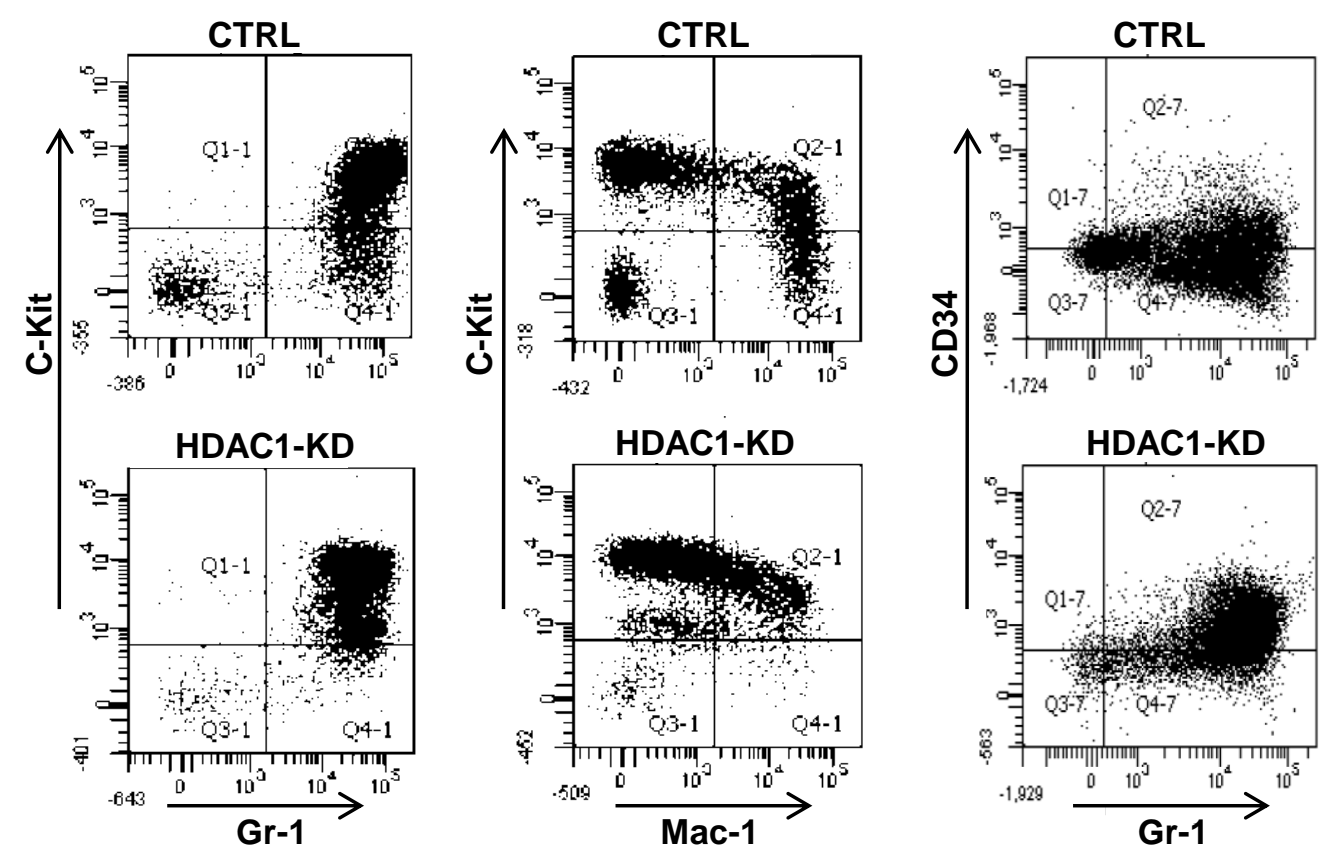

Figure 1 

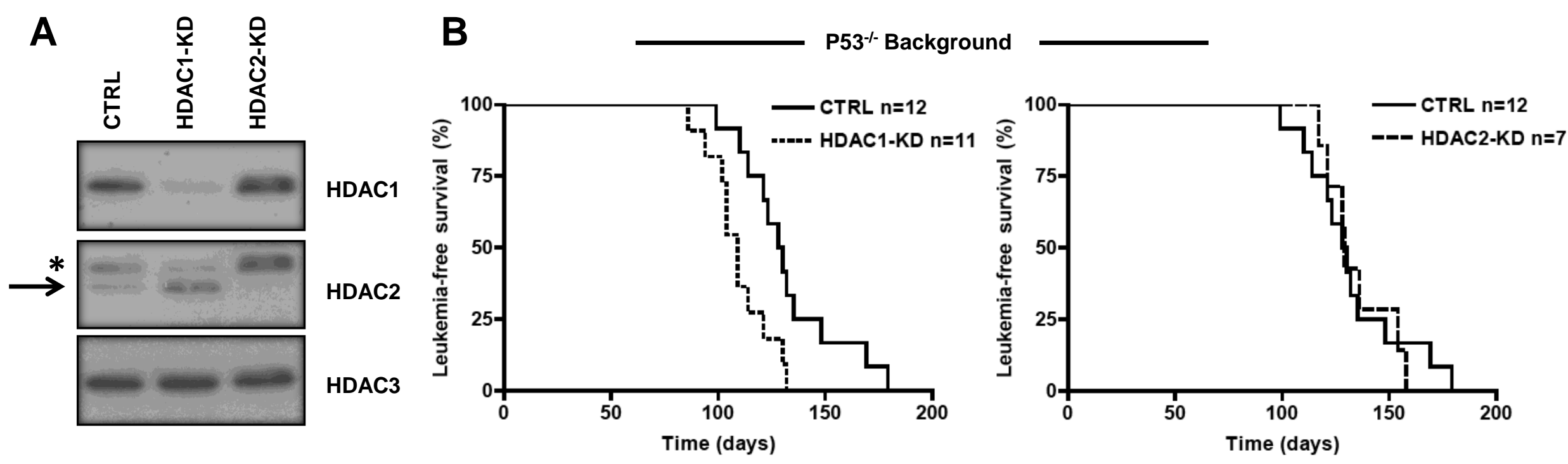

C

$E \mu M y c$ Background

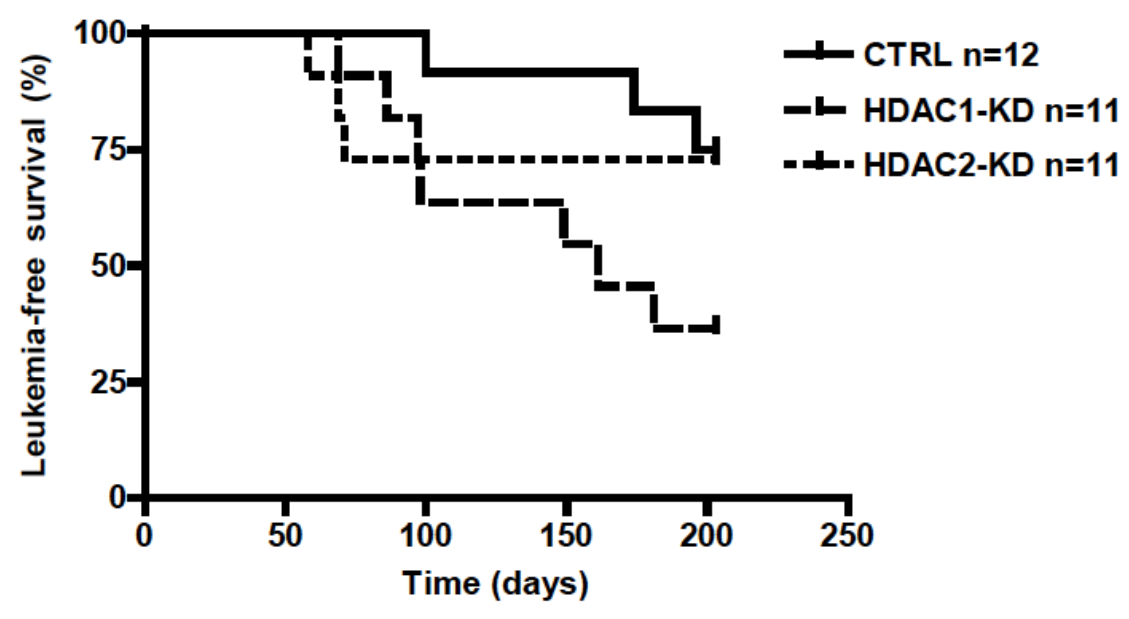

D

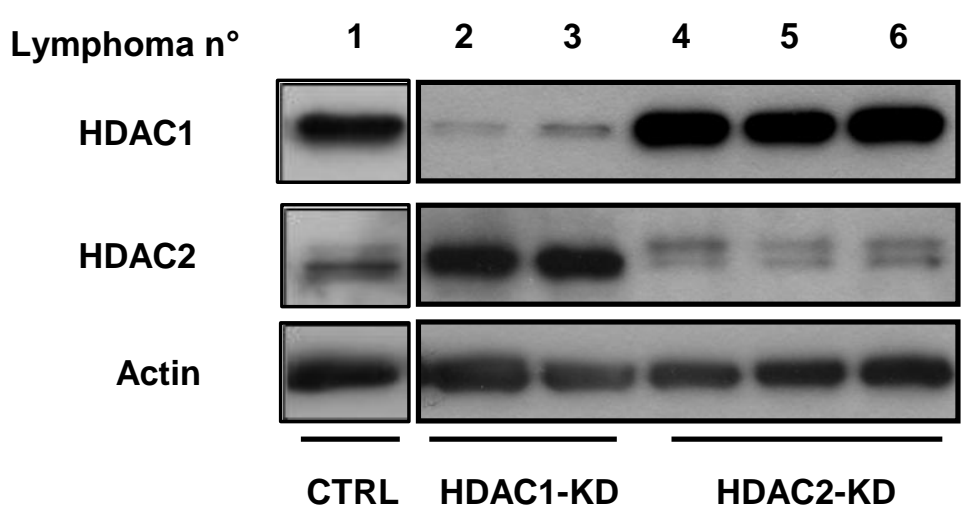

Figure 2 
A
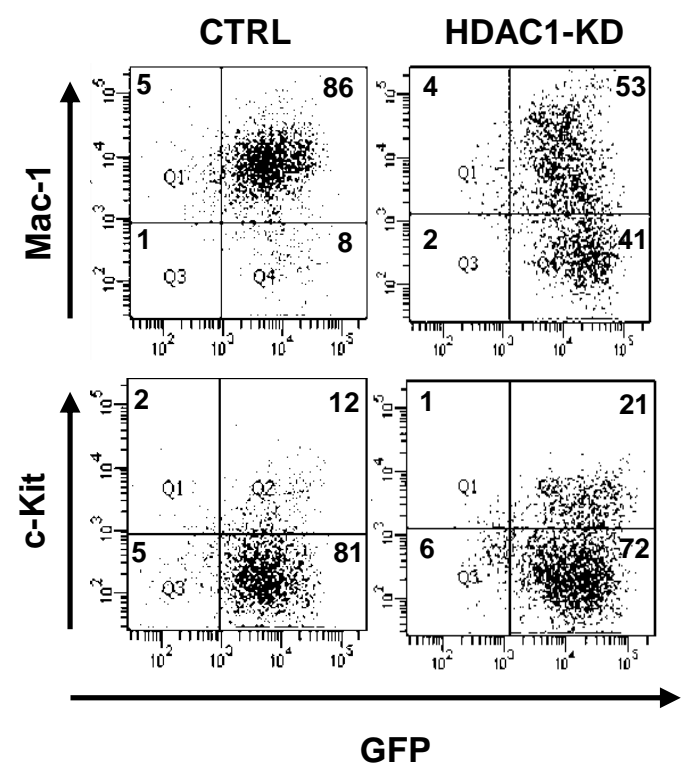

C

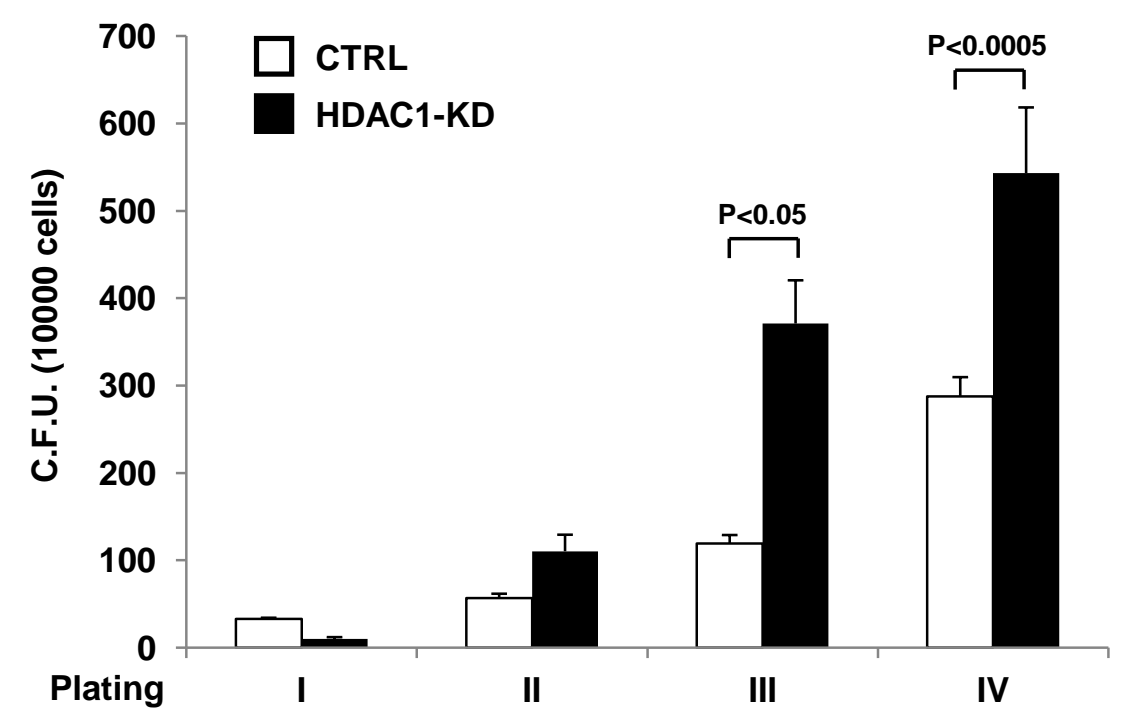

B
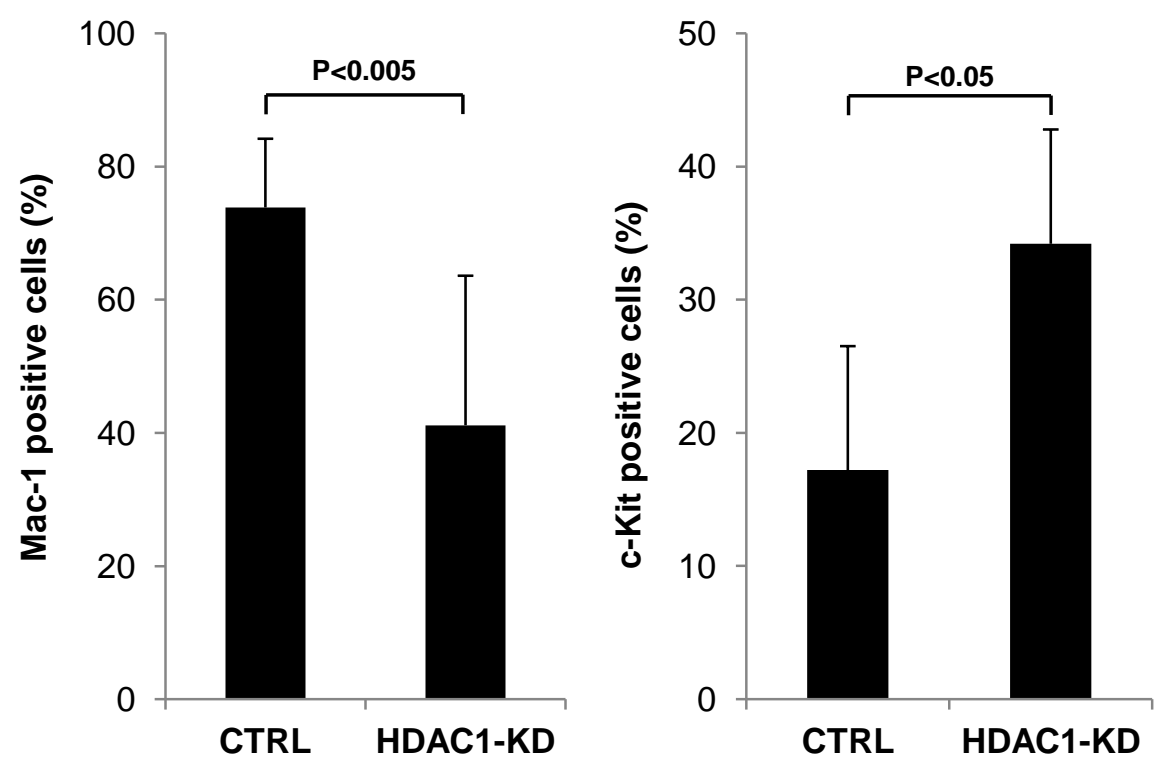

D

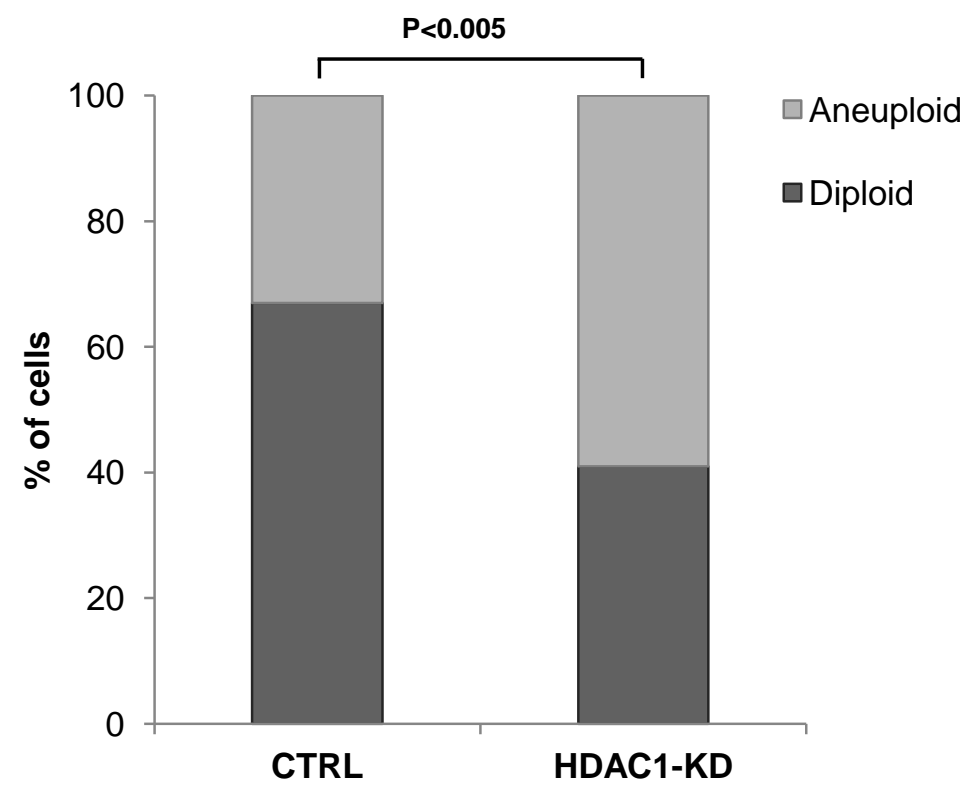

Figure 3 
A

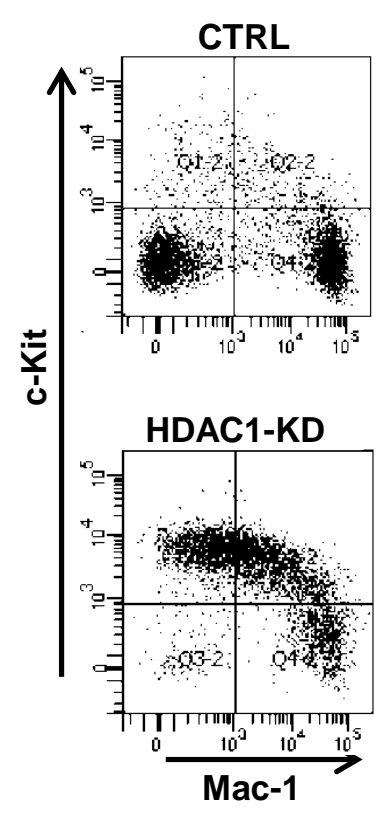

D

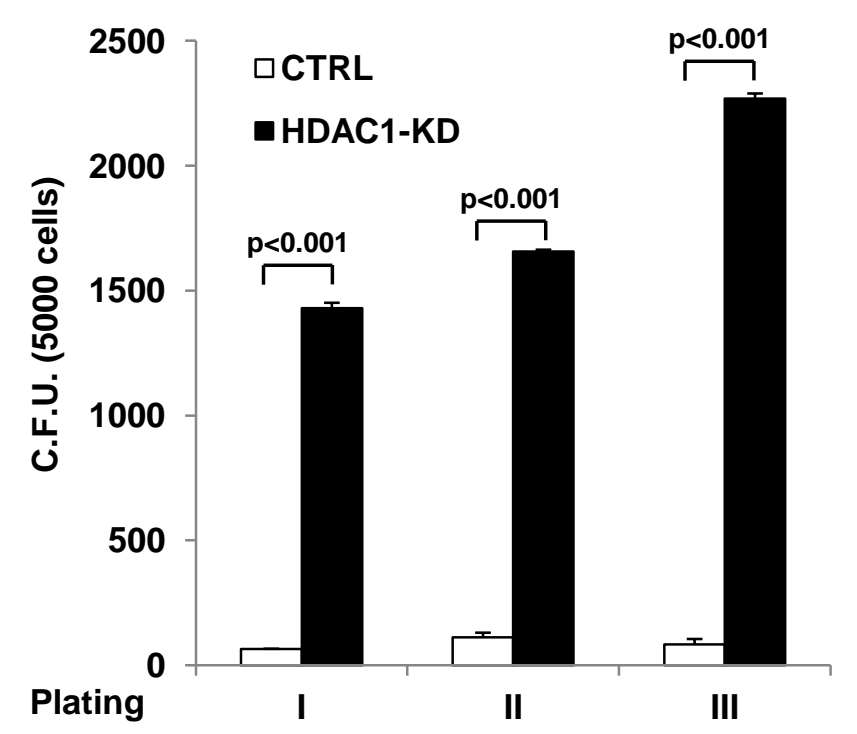

B
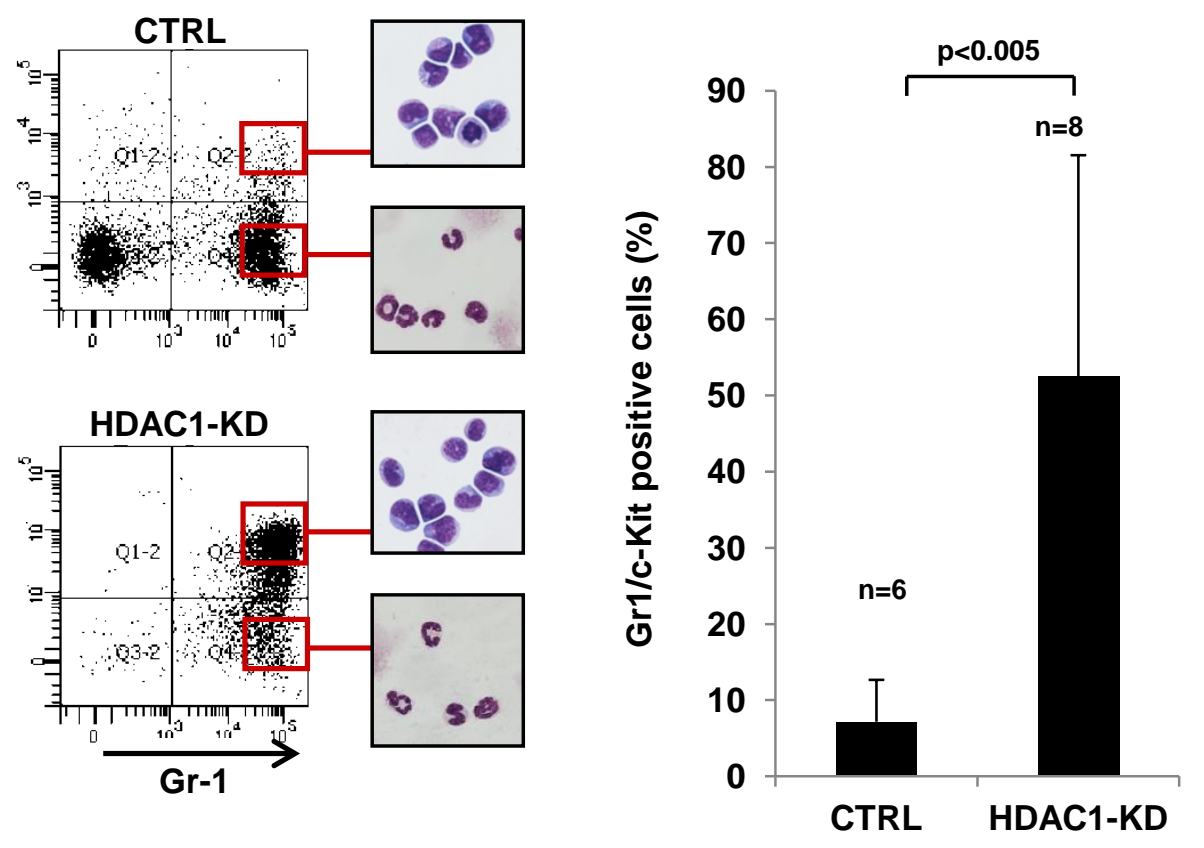

E
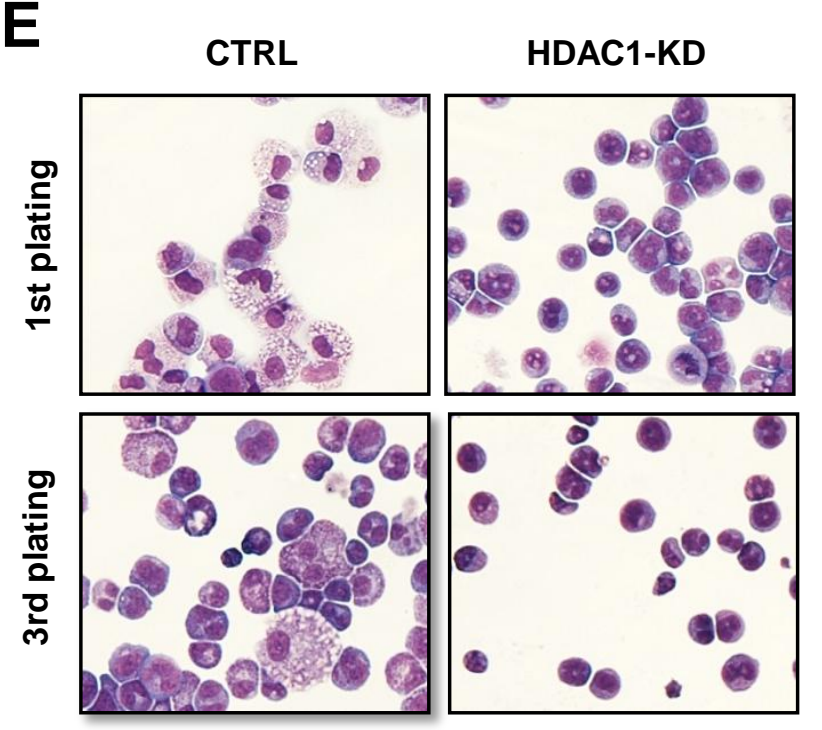

C
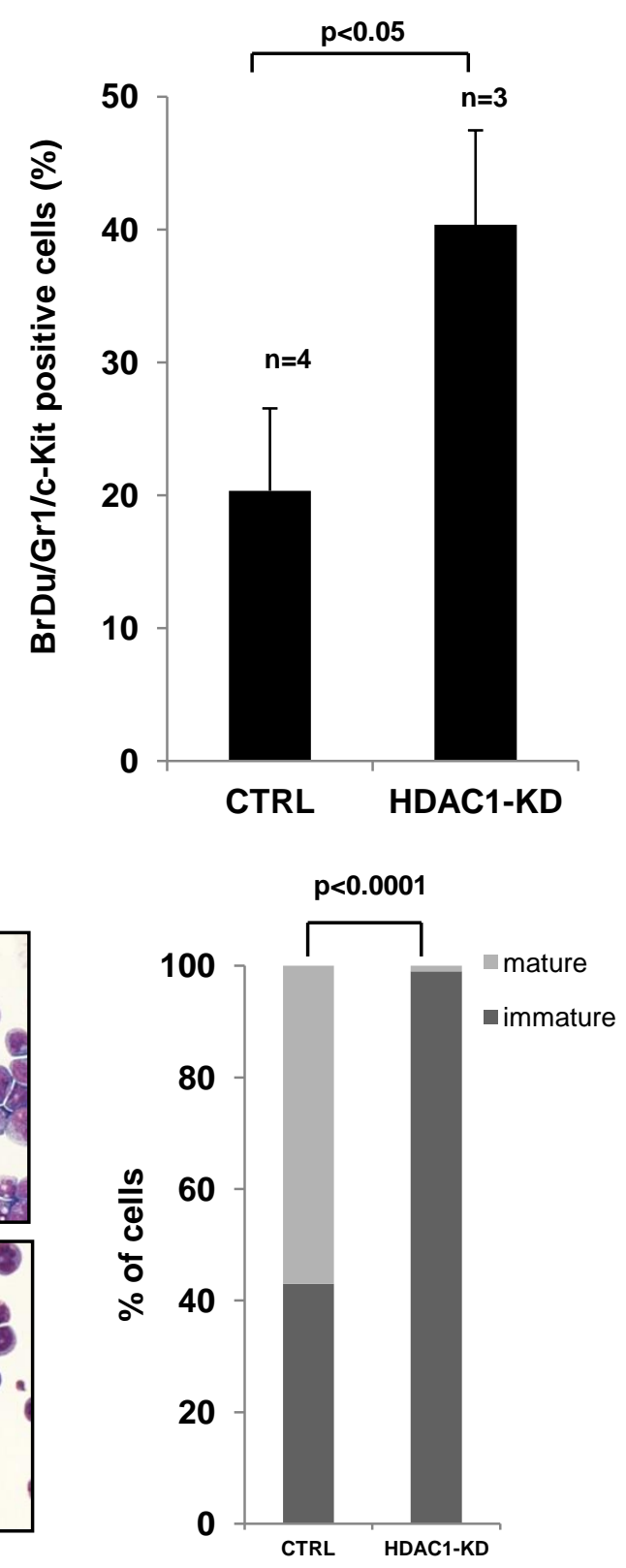

Figure 4 


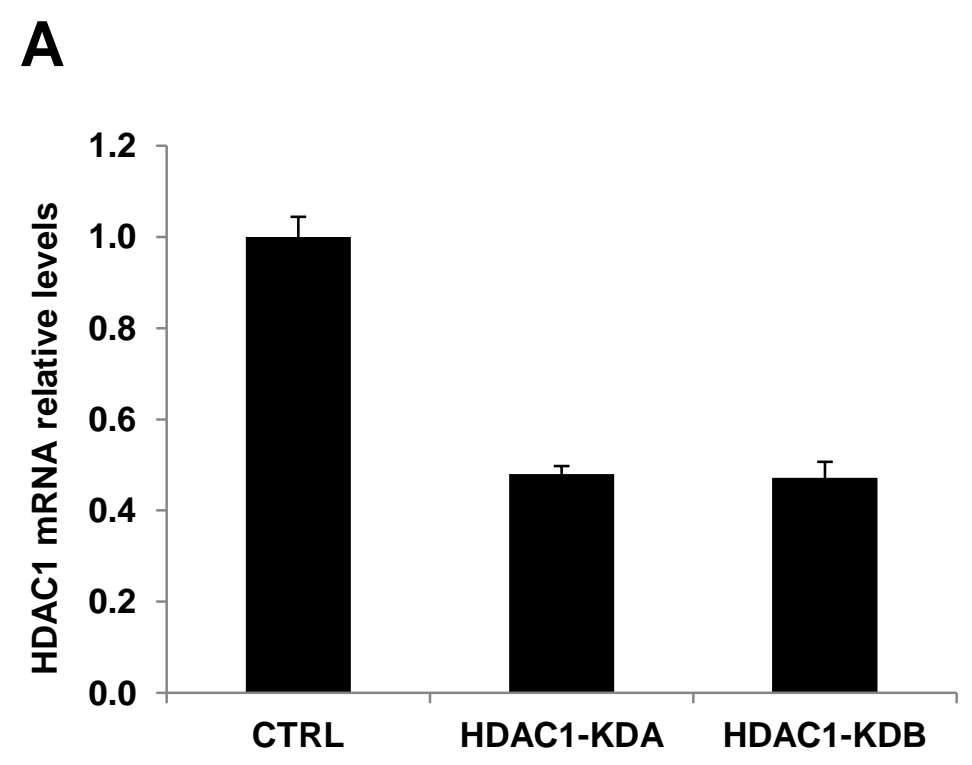

B

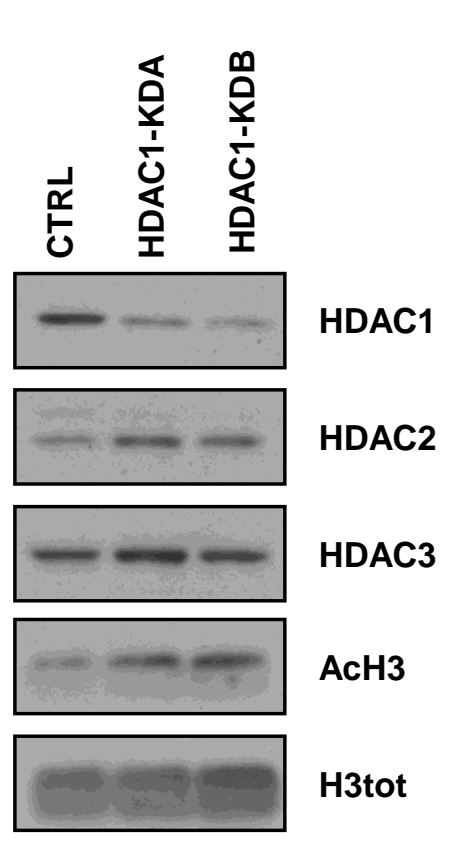

C
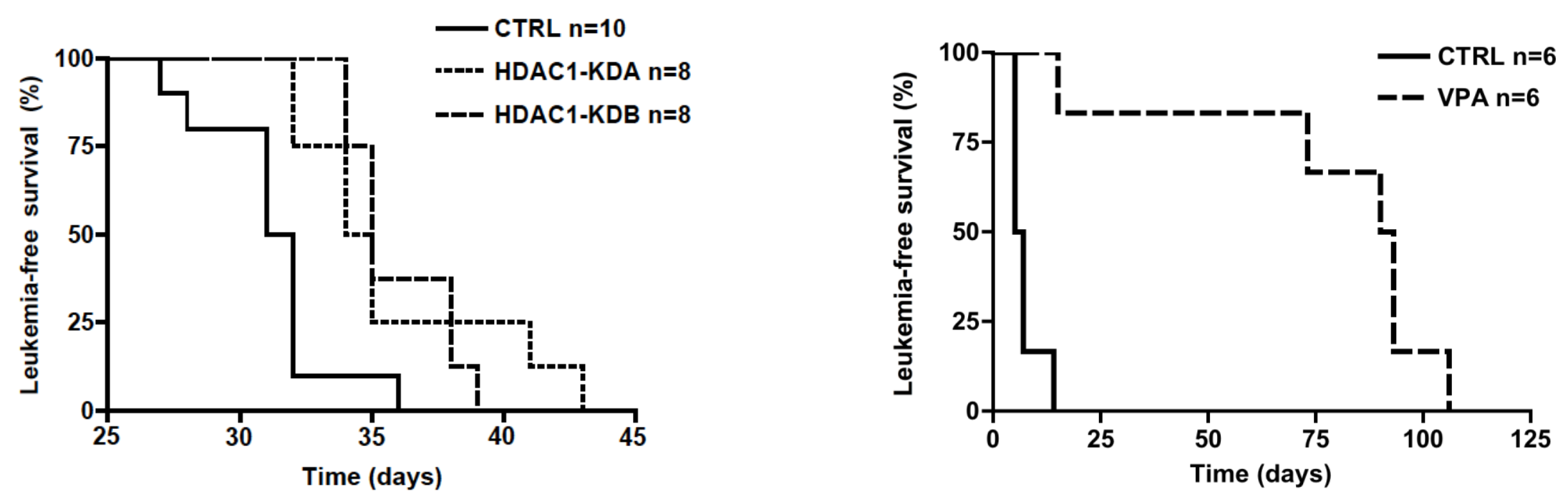

Figure 5 
A
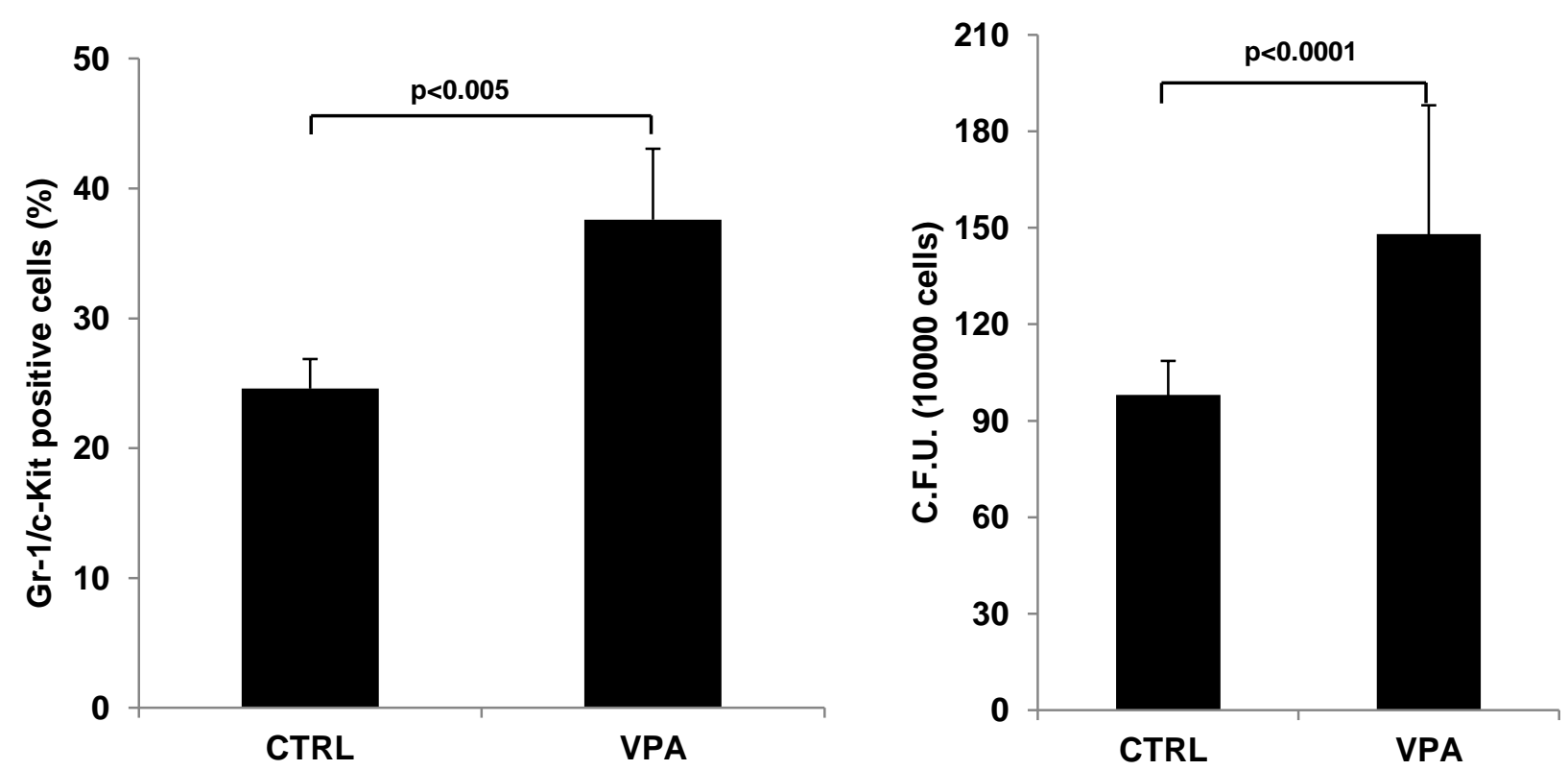

B

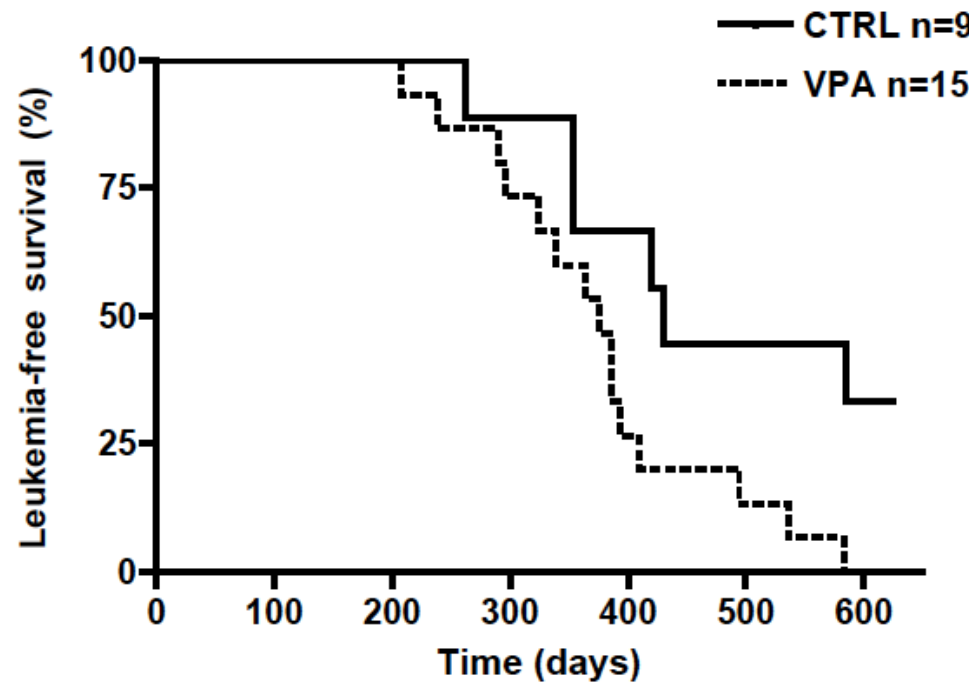

Figure 6 